\title{
ARWALK: A Tool to Assist Indoor Navigation with Augmented Reality
}

\author{
Arthur Galdino Dangoni \\ Pontifícia Universidade Católica de \\ Goiás, \\ PUC Goiás Goiânia/GO Brasil
}

\author{
Lutyéllen dos Santos Ribeiro \\ Pontifícia Universidade Católica de \\ Goiás, \\ PUC Goiás Goiânia/GO Brasil
}

\author{
Talles Marcelo G. de A. \\ Barbosa \\ Pontifícia Universidade Católica de \\ Goiás, \\ PUC Goiás Goiânia/GO Brasil
}

\begin{abstract}
Augmented reality is a useful technology for learning about people with Down Syndrome (DS). These people have impaired psychomotor skills in addition to having difficulties in understanding. This work proposes to create an internal navigation application with an augmented reality interface. It allows for greater autonomy and well-being of these people, supporting them in this type of environment. Based on tests performed in simulated environments, it can be useful for people with difficulties in locomotion and understanding.
\end{abstract}

\section{General Terms}

System software, Augmented Reality, Personal Assistant.

\section{Keywords}

Indoor navigation, Marker-based AR, Android.

\section{INTRODUCTION}

Augmented reality (AR) is a technology that allows virtual elements to view the real world interactively and in real-time [1]. This technology allows the user to see the whole world with virtual objects or information superimposed on top. These objects appear on the smartphone interface as if they were present in the real world. AR can be useful for giving places an additional sense, for arousing curiosity and interest in people, and increasing the interaction between the user and the application [2], [3], [4]. There are three AR types: (i) based on a marker, (ii) markerless projection, and (iii) superimposition [5].

Joshi et al. [5] define marker-based AR as a technology that generates a digital image from identifying images (markers). Simultaneously, markerless AR is a technology that uses sensors to detect the environment and thus cause the AR interface. These sensors can be GPS, accelerometers, and speed meters. Projection-based AR projects light in the real world onto surfaces, and human interaction with light is seen. This process is accomplished by distinguishing between the expected and the changed projection. Finally, superimposition AR detects and recognizes objects and then overlays them with a digital image.

Navigation is the task of finding a path from your current location to reach your destination and how that path is constructed. Navigation within an indoor environment presents some additional difficulties due to signal attenuation and restricted access places. Thus, the most used indoor navigation techniques are RFID, magnetic flashlights, markerbased AR, and markerless AR [5].

In the study developed by [6], it was proven that the use of GPS with the AR interface is inappropriate. In this study, the $3 \mathrm{D}$ direction of the AR interface showed many errors. The
GPS did not present an exact location, as it had errors of a few meters. It caused the AR interface to point out incorrect directions like going through a building.

In [7], a navigation application for the population of wheelchair users is proposed. This study was considered to be challenging to move into this type of people. The application considered stairs and obstacles in calculating the route. This system used marker-based RA technology. In addition to registering $\mathrm{CAD}$ drawings for positioning the markers, allowing the system's use in different places. This study conducted tests at a school with people in wheelchairs. The results of the tests showed that the markers were identified with precision.

Several studies have shown the effectiveness of the AR interface for people's navigation. Gupta et al. [8] proposed mapping and location of an indoor environment with an AR interface. The fusion of inertial sensors with visual odometry was used. Malek, Sebastian, and Drieberg [9] developed an embedded platform for indoor navigation with AR to create an indoor navigation tool instead of smartphones. Gladston and Duraisamy [10] proposed an application for indoor navigation in new or unknown places.

Kasprzak, Komninos and Barrie [11] used marker-based AR technology. They developed an application to identify the brands of famous places inside a mall to give direction. The marks of these places were used for not having to place specific markers in place. This work used this technology, as the markerless AR technology is more prone to errors or needs a significant infrastructure. In contrast, AR technology with a marker for indoor environments is easily accessible. Through the tags, the location and precise information of the places can be generated.

Down syndrome (DS) is a genetic anomaly with some physical and behavioral characteristics that generate different personalities. Some of these characteristics can cause movement, speech, hearing, and learning [12]

The study developed in [13] proposed using cell phones in people with DS's job training. QR Codes are placed in places close to daily activities. When identifying these QR Codes, a tutorial is given on how to do that activity. The interface was designed to be simple because of the difficulties that people with DS have. Through questionnaires, this study showed that the time, the number of errors, and requests for help were less than the traditional teaching method. From these results, the identification of QR Codes using the cell phone camera is useful. In addition to showing the usefulness of using technology for training these people.

Some studies demonstrate the importance of $\mathrm{AR}$ in the 
population of DS. Souza et al. [14] proposed an AR-based application to support people's literacy process with DS. This application identified images, and from them, a virtual object is generated on the cell phone screen with its respective name and initial letter. Tests carried out on the SD population showed that the application is valid for this type of people. They were obtaining more significant user interaction with the application and stimulating and facilitating students' knowledge.

Cakir and Korkmaz [4] proposed a study to verify AR's effectiveness in environments for people with special needs. They created 3D animations to create a more interactive environment. The tests were done to teach essential content like math and the seasons. They conducted questionnaires on the contents taught. From these questionnaires, they concluded that AR in this environment increases people's creativity and motivation. They were enabling AR to be applied to the primary education of people with special needs.

This article proposes the development of an application for indoor navigation using an AR interface. To train people with DS to develop autonomy in locomotion in indoor environments.

\section{Methodology}

Based on DS people's requirements, including indoor navigation difficulties, a development process based on successive refinements was chosen, as shown in the activity diagram in Figure 1. This type of process is used when it is not possible to identify all requirements immediately. In the course of development, these requirements are identified. The implementation of the prototype started when the first requirements were obtained. When the prototype ends, an analysis is carried out to verify that it has met all requirements. If all requirements were not met, a new implementation was carried out to meet the new requirements. Finally, a test step was performed to verify the prototype's functionalities. In this step, some test cases were created to test the tool. In this way, the functionalities were checked, and if any interface could be subject to improvements.

\subsection{Requirements}

The requirements of this work comprise the implementation of a simple interface. It enables the insertion of a new scenario using markers to give direction and a character to interact with the user. Use of audio and text for assistance. The text must be in all capital letters and in bold. Finally, the search algorithm for the shortest path must take into account the user's psychomotor skills.

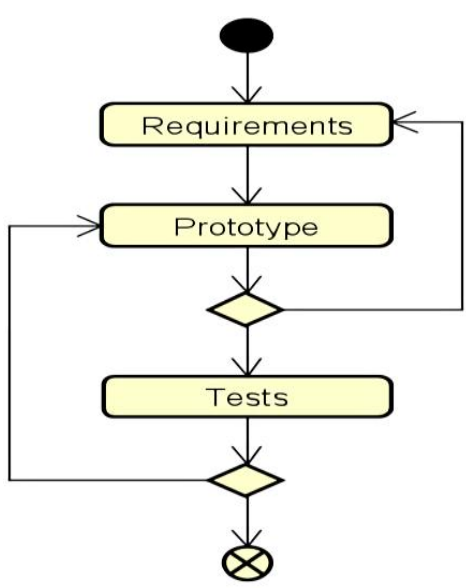

Fig 1: The Development Process

These requirements were identified based on DS's people but can be used on older people and children who have motor and comprehension difficulties. A part of the requirements was determined from the literature review. At the same time, the others were identified through weekly meetings with health professionals. These professionals participate in a support project for people with DS.

\subsection{Prototype}

Based on the initial requirements, prototyping was started, thought of developing the prototype for people with DS. However, due to the difficulty of carrying out tests due to the Covid-19 pandemic. Thus, the application was adapted to be any type of person according to their psychomotor ability level. Besides, three types of users were identified from the requirements, as shown in Fig 2. The first type of user may be responsible for children or people with DS. In addition to being ordinary users who have access to all the functionality of the software. The second type of user is the users who used the application's navigation system. These users are people with or without problems with understanding. Finally, the third user is responsible for inserting the location map and configuring its psychomotor skill level.

From these users, screen prototypes were defined, considering the role of each user. The initial screen for choosing a destination is shown in Fig 3. This screen was considered the requirement to have a simple interface and was defined as the first type of user. This user will choose the destination for the user who has a comprehension problem to navigate the place.

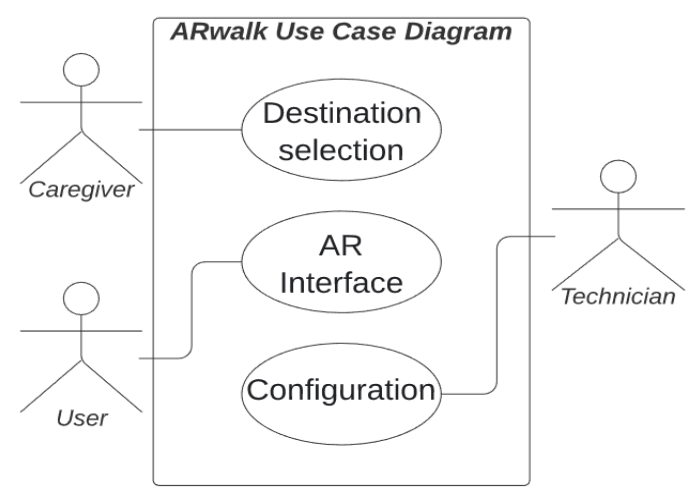

Fig 2: ARwalk Use Case Diagram 


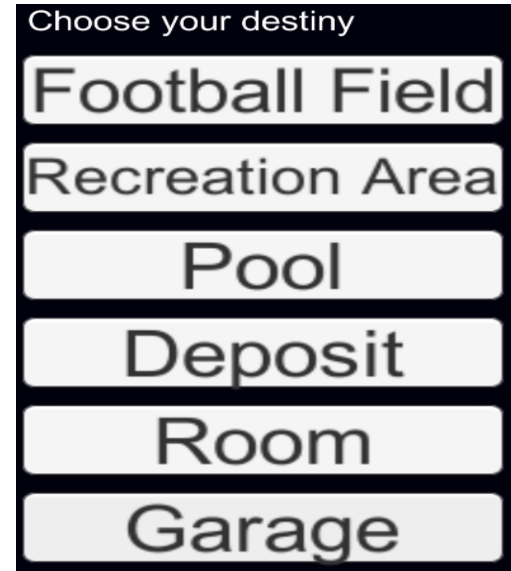

Fig 3: Destination Selection Screen

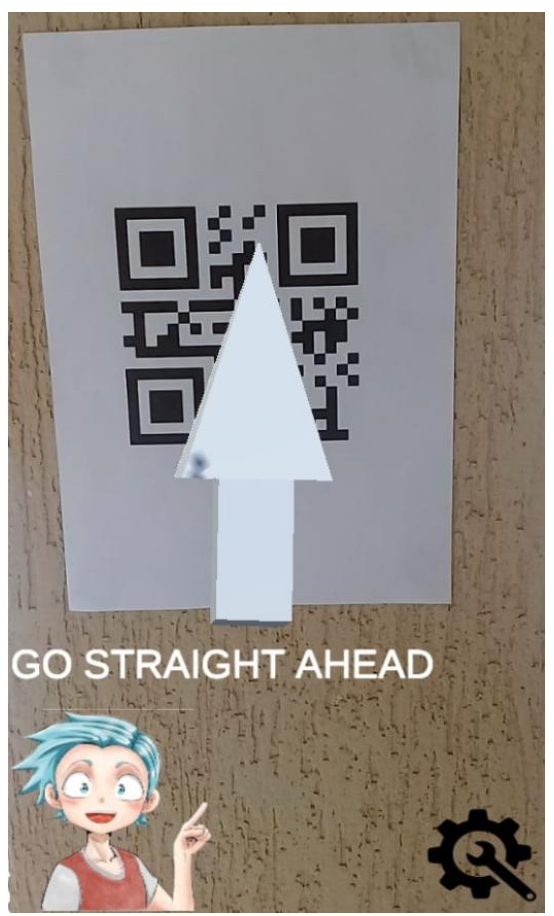

Fig 4: AR App Screen

After the destination is chosen, the AR interface is shown, which also has a simple interface. This interface considered the markers' identification to give direction and assess the character, audio, and text requirements. When identifying a tag, the character, and the direction, will appear along with the audio, as shown in Fig 4. There are specific audios for each given order and having a case the user reaches the destination. This screen was built for the second type of user.

While the screens in Fig 5 to Fig 8 were defined for the third type of user. As there will be no described scenario on the first run of the application, a configuration option appears. The settings offer instructions options that show how the map is created. Finally, you have options to create the map, start the application, and define the user's psychomotor skill level, as shown in Fig 5. Fig 5 shows a configuration option to allow changing the map and the user's psychomotor ability. Access to these settings is done only by the third user. For this, a system was implemented using authentication through a password, as shown in Fig 6. The screen for creating the map was considered the requirement to insert a new environment.
It is possible to load an environment defined before or create a unique environment, as shown in Fig 7. When loading a new environment, the file must contain the following parameters, as shown in Fig 8. First, the number of vertices is necessary. After that, it has a list with all the edges and their directions. If one of the vertices is a stair at the border, the letter " $\mathrm{S}$ " is inserted before the starting vertex-finally, a list of all possible destinations.

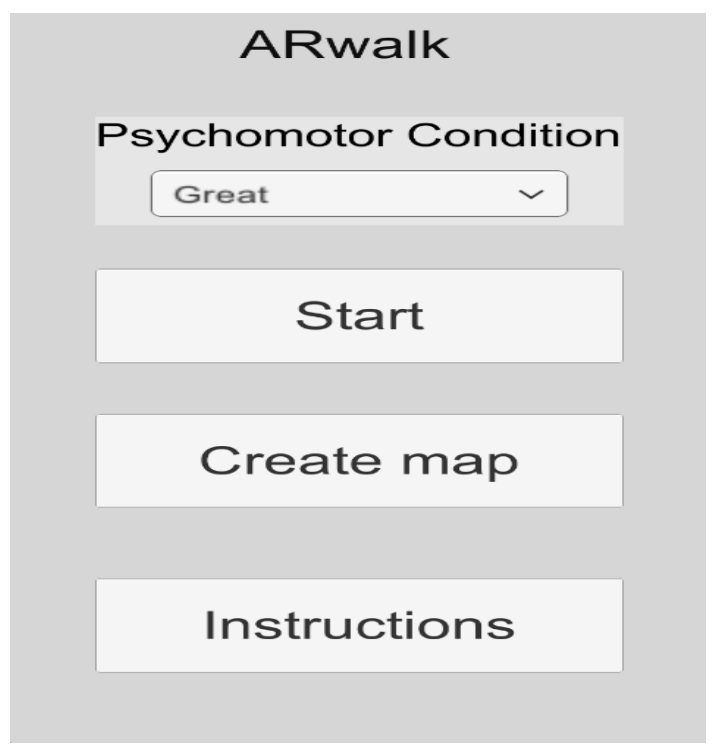

Fig 5: Options Screen

Type the password:

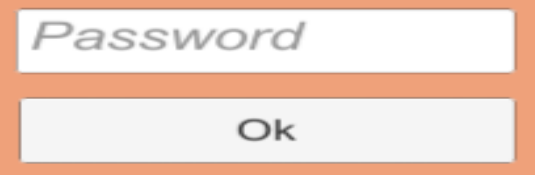

Fig 6: Password screen

Insert the map

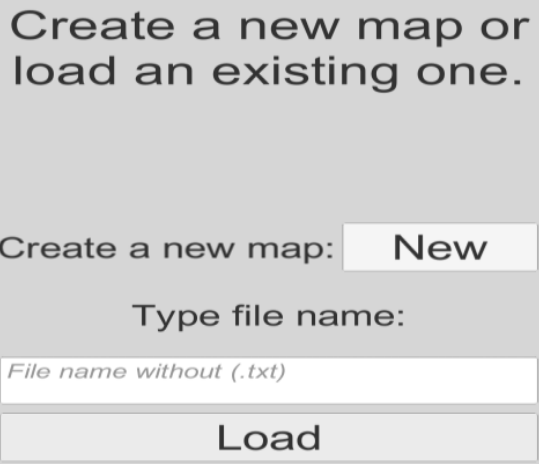

Fig 7: Screen to create or load a map 


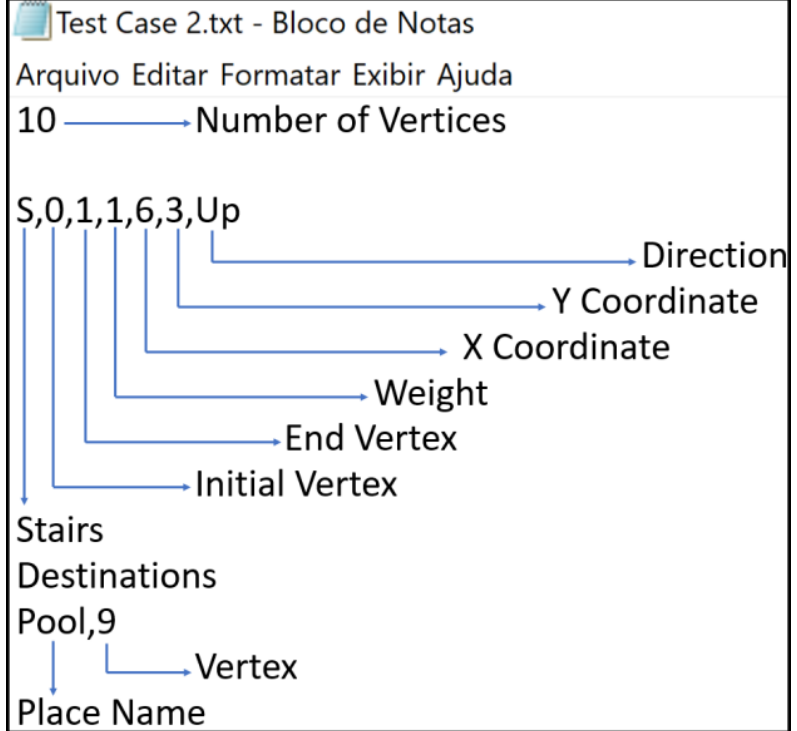

Fig 8: File Content

\subsection{Tests}

Test cases were built to see if the tool could be functional. Two test cases were defined. The first test case is a representation of a school. This school has two floors, containing one elevator and one staircase, with 34 markers. While the second test case represents one house with one floor, having ten tags, as shown in Fig 8.

In Fig 9, each star represents a marker put in place; that marker is an image used to give directions. Markers are placed at each point that has a fork and at destinations. Every room in the house is a possible destination.

From the representation of the place, it is possible to build a coordinate map shown in Fig 10. Using these two representations, the construction of the directed graph that will be inserted in the application.

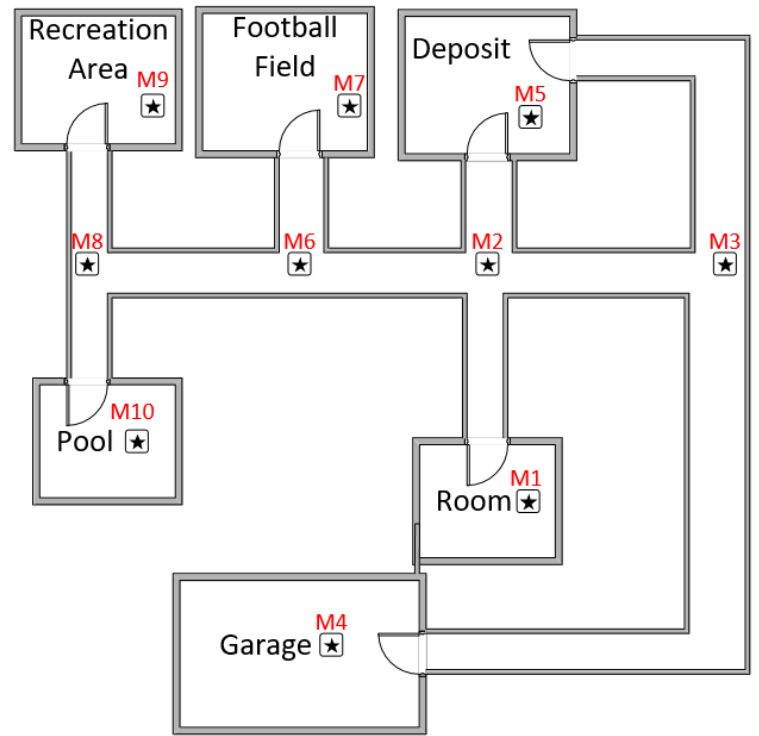

Fig 9: Physical Parts of a House
A chart is a data structure that represents the place. This graph has vertices and edges, the vertices being the markers. The coordinates of each vertex are used to calculate the heuristic distance. Finally, the edges are represented by the adjacent tags. A direction and its weight are added to the edges. The consequences represent the distances between the markers. These weights are represented by the number of fields between two vertices. These fields follow a scale with each area equivalent to $50 \mathrm{~m} 2$, as shown in Fig. 10.

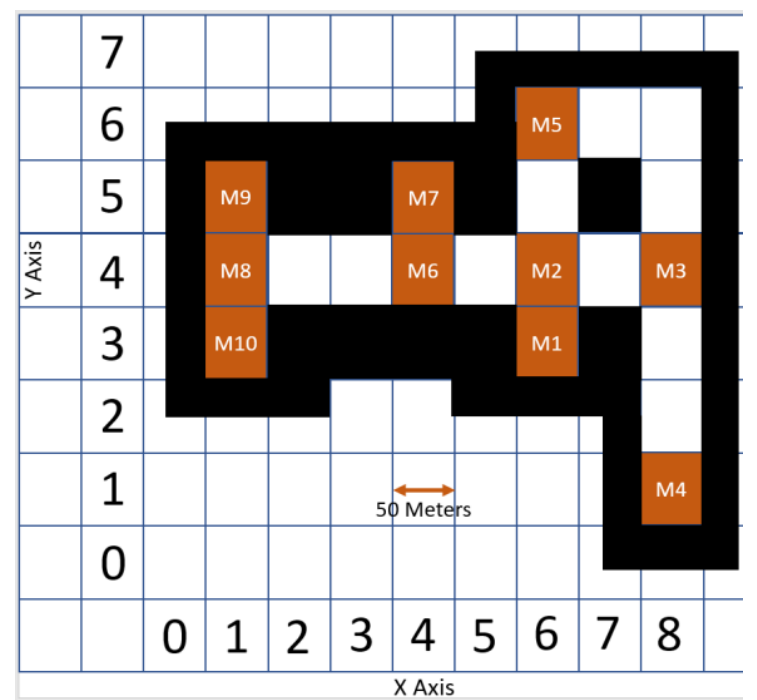

Fig 10: Map Relative to Fig. 9

From the graph, it is possible to calculate the shortest path using an algorithm. A comparison was made between 3 algorithms, being Dijkstra [15], A star (A *) [16], and Greedy Search [15]. The last two algorithms need a heuristic distance. The calculation of this heuristic distance was that of manhattan, as it is a straight line calculation from the current vertex to the destination. This calculation was chosen because it is admissible. It is permissible because it satisfies equation (1), where $\mathrm{h}(\mathrm{n})$ is the heuristic distance from any vertex, and $\mathrm{g}$ is the space's uniform cost and taking into account that the user will always walk in a straight line to the next marker.

$$
\boldsymbol{h}(\boldsymbol{n}) \leq \boldsymbol{g}(\boldsymbol{n})
$$

The algorithm considers the user's least physical effort, as DS users may have difficulties moving. In an environment with two floors, as is the school test case, when navigating to the 2nd floor, the user has to go through a stair or elevator. The elevator does not require an effort from the user, while the stairway requires this physical effort. According to the user's psychomotor skill level, it is considered to travel a distance to go by elevator or stairs. In the graph, this is considered as follows. When there is a vertex representing a stair between two floors, $x$ units are added to the weight on that edge. For this, the edges represent the connection between two floors; being elevators or stairs must have the same weight. This $\mathrm{x}$ value is calculated according to your level of psychomotor skill, as shown in Table 1. In this way, the algorithms that use weight will converge to a route with an elevator according to the user's psychomotor skill. 
Table 1: Psychomotor Condition Table

\begin{tabular}{|l|l|l|}
\hline $\begin{array}{l}\text { Psychomotor } \\
\text { Condition }\end{array}$ & X units & Real distance \\
\hline Great & 0 & 0 \\
\hline Good & 1 & 50 meters \\
\hline Normal & 2 & 100 meters \\
\hline Bad & 4 & 200 meters \\
\hline Debilitated & 8 & 400 meters \\
\hline
\end{tabular}

Table 2 shows the number of vertices that each algorithm covered in the two test cases, considering all possible paths. The Greedy Search algorithm has a lower computational cost, but it is not possible to use it. The calculation of this algorithm's route is done, considering only the heuristic distance. That is, the physical effort is disregarded. The A * algorithm was chosen because the heuristic distance and the physical effort represented by the weights are considered when calculating the way. As long as the heuristic distance is permissible, A* has an optimal solution. The calculation for considering which vertex should be followed is shown in equation (2). In this equation, the cost of the vertices is $g(n)$. While $h(n)$ represents the heuristic distance from the current vertex to the destination vertex.

Table 2: Comparative Table

\begin{tabular}{|l|l|l|}
\hline & School & House \\
\hline A Star $\left(\mathrm{A}^{*}\right)$ & 15227 & 257 \\
\hline Dijkstra & 19074 & 450 \\
\hline Greedy Search & 13708 & 228 \\
\hline
\end{tabular}

$$
\boldsymbol{F}(\boldsymbol{n})=\boldsymbol{g}(\boldsymbol{n})+\boldsymbol{h}(\boldsymbol{n})
$$

This project's prototype used the technologies Unity 3D, Vuforia, Android SDK (Software Development Kit), and Blender. The $\mathrm{C}$ \# language was used to implement the application in Unity 3D. In Blender, the 3D arrow was implemented to give the direction, and this software was chosen because it has more manageable and more intuitive modeling. Unity 3D was selected because it has a shorter learning time. Because the time spent using Vuforia with Unity 3D is low, as Vuforia is natively integrated with Unity $3 \mathrm{D}$. Allowing the development of functional prototypes in less time.

White-box tests were performed to verify that the algorithm was converging to the shortest route. In addition to checking the insertion of a new scenario and the loading of an old scenario. Black box tests to verify requirements. For that, scenarios were created in addition to trying to load a nonexistent scenario. Tests were performed with images other than QR Codes. However, these images should have additional meaning, such as a photo of the current location. Finally, it was decided to use QR Codes, as they are more generic. Another test that was carried out is about the size of these QR Codes. In the trials, two dimensions were tested, 600 pixels and 150 pixels. Fig 11 shows the comparison between the number of characteristics between these QR Codes.

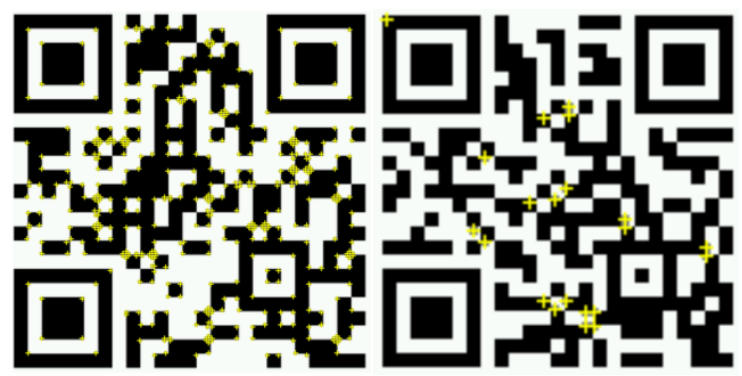

Fig 11: Characteristics of QR codes in 600 pixels and 150 pixels, respectively

\section{RESULTS AND DISCUSSIONS}

Comparing the algorithms shows that the $\mathrm{A}^{*}$ algorithm is the best choice for this prototype. When loading a non-existent scenario, the prototype did not present any error and continued to work with the current scenario. Through the analysis of characteristics between the QR codes of 600 pixels and 150 pixels. The cell phone camera and the vuforia engine to identify these characteristics in the images showed that the QR codes of 150 pixels obtained a better result. With smaller pictures, the features are smaller, allowing faster identification of markers and more accurate identification. This prototype can position 35 images, allowing 35 points of interest. These images are QR Codes with a size of 150 pixels.

No indoor navigation application using an Augmented Reality interface for the DS population was found in the literature. Therefore, this study considered the difficulties of this type of people to obtain the requirements. This study allows the user to have more autonomy and well-being in people's movement through indoor environments. Testing on individuals was not possible due to the covid-19 pandemic.

\section{CONCLUSION}

This article presents an application for indoor navigation using an AR interface for the population with DS. However, the application proved useful for people who do not have DS, such as children and the elderly. According to the results and related work, the results demonstrated to meet all the tests' identified requirements. It presents a promising approach to conduct training on people to have greater autonomy when moving around an indoor environment. A version of this prototype is available at https://github.com/NishinoTSK/ARwalk

For future work, it is proposed to add a system for the user to insert their markers, removing the limit of 35 images. Finally, carry out the DS population tests to verify this study's usefulness in a real environment. These tests can be carried out in the Alfadown extension project at PUC-Goiás, which offers support for people with DS. Through activities that use computer resources for personal development, teaching the alphabet [17]. 


\section{ACKNOWLEDGMENTS}

Thanks to the people of the Alfadown project, who showed the difficulties that people with DS have. Also, thanks to contributions from Vitor de Almeida Silva.

\section{REFERENCES}

[1] PELEG-ADLER, Rinat; LANIR, Joel; KORMAN, Maria. The effects of aging on the use of handheld augmented reality in a route planning task. Computers In Human Behavior, [S.L.], v. 81, p. 52-62, abr. 2018. Elsevier BV.

[2] CHU, Chung-hua; Wang, Shu-lin; Tseng, Bi-chi. Mobile navigation services with augmented reality. IEEJ TRANSACTIONS ON ELECTRICAL AND ELECTRONIC ENGINEERING,2017, Wiley Online Library.

[3] LIAO, Tony; HUMPHREYS, Lee. Layar-ed places: using mobile augmented reality to tactically reengage, reproduce, and reappropriate public space. : Using mobile augmented reality to tactically reengage, reproduce, and reappropriate public space. New Media \& Society, [s.1.], v. 17, n. 9, p. 1418-1435, 19 mar. 2014. SAGE Publications.

[4] CAKIR, Recep; KORKMAZ, Ozgen. The effectiveness of augmented reality environments on individuals with special education needs. Education And Information Technologies, [S.L.], v. 24, n. 2, p. 1631-1659, 15 dez. 2018. Springer Science and Business Media LLC

[5] JOSHI, Rhuta; HIWALE, Anuja; BIRAJDAR, Shivani; GOUND, Renuka. Indoor Navigation with Augmented Reality. Lecture Notes In Electrical Engineering, [S.L.], p. 159-165, 2 ago. 2019. Springer Singapore.

[6] REHRL, Karl; HÄUSLER, Elisabeth; LEITINGER, Sven; BELL, Daniel. Pedestrian navigation with augmented reality, voice and digital map: final results from anin situfield study assessing performance and user experience. Journal Of Location Based Services, [S.L.], v. 8, n. 2, p. 75-96, 3 abr. 2014. Informa UK Limited. http://dx.doi.org/10.1080/17489725.2014.946975.

[7] OLIVEIRA, Luciene Chagas de; SOARES, Alcimar Barbosa; CARDOSO, Alexandre; ANDRADE, Adriano de Oliveira; LAMOUNIER JÚNIOR, Edgard Afonso. Mobile Augmented Reality enhances indoor navigation for wheelchair users. Research On Biomedical Engineering, [s.1.], v. 32, n. 2, p. 111-122, 24 maio 2016. FapUNIFESP (SciELO).

[8] GUPTA, G.; KEJRIWAL, N.; PALLAV, P.; HASSAN, E.; KUMAR, S.; HEBBALAGUPPE,R. Indoor localisation and navigation on augmented reality devices. In: IEEE.2016 IEEEInternational Symposium on Mixed and Augmented Reality (ISMAR-Adjunct). [S.1.],2016. p. $107-112$

[9] MALEK, M. F. bin A.; SEBASTIAN, P.; DRIEBERG, M. Augmented reality assistedlocalization for indoor navigation on embedded computing platform. In: IEEE.2017 IEEEInternational Conference on Signal and Image Processing Applications (ICSIPA). [S.1.],2017. p. 111-116.

[10] GLADSTON, A.; DURAISAMY, A. Augmented reality indoor navigation using handhelddevices.International Journal of Virtual and Augmented Reality (IJVAR), IGI Global,v. 3, n. 1, p. 1-17, 2019.

[11] KASPRZAK, Sebastian; KOMNINOS, Andreas; BARRIE, Peter. Feature-Based Indoor Navigation Using Augmented Reality. 2013 9Th International Conference On Intelligent Environments, [S.L.], jul. 2013.

[12] Vanessa Helena Santana Dalla Déa, Edison Duarte. "Síndrome de Down: informações, caminhos e histórias de amor." - São Paulo: Phorte, 2009.

[13] GOMEZ, Javier; TORRADO, Juan Carlos; MONTORO, Germán. Using Smartphones to Assist People with Down Syndrome in Their Labour Training and Integration: a case study. Wireless Communications And Mobile Computing, [S.L.], v. 2017, p. 1-15, 2017. Hindawi Limited.

[14] SOUZA, Dayane de; TRINDADE, Genarde; FERNANDES, Priscila Silva; BONIFÁCIO, Bruno. AlfabetzAR: uma aplicação móvel com base na realidade aumentada como ferramenta de apoio no processo de alfabetização de portadores de síndrome de down. Anais do XXVIII Simpósio Brasileiro de Informática na Educação (Sbie 2017), [S.L.], p. 0-0, 27 out. 2017 Brazilian Computer Society (Sociedade Brasileira de Computação - SBC)

[15] Thomas H Cormen, Charles E Leiserson, Ronald L Rivest, and Clifford Stein. Introduction to algorithms. MIT press, 3rd edition, 2009.

[16] Russell, S. J. and Norvig, P. (2013). Artificial Intelligence: A Modern Approach. Pearson Education, 2 edition.

[17] SOUSA, M. V. G.; RAMOS, D.; CASTRO, L. X. de; CRUZ, M.; HANNUM, J. S. de S.;BARBOSA, T. M. G. d. A. Lori's help: um aplicativo para auxílio na alfabetização de pessoas com síndrome de down.Revista Brasileira de Computação Aplicada, v. 9, n. 2,p. 2-13, 2017. 